\title{
Copula Based Spatial Analysis of Drought Return Period in Southwest of Iran
}

\author{
Mohammadreza Kavianpour ${ }^{1}$, Mohammadreza Seyedabadi, Saber Moazami², \\ Omid Aminoroayaie Yamini ${ }^{1}$
}

\author{
1 Department of Civil Engineering, Khajeh Nasir al-Din Tusi University of Technology, Tehran 1969764499, Iran \\ ${ }^{2}$ Water Resources Engineering Research Assistant, Western University, 1151 Richmond Street, London, Ontario N6A 3K7, Canada \\ * Corresponding author, e-mail: seyedabadi@alumni.ut.ac.ir
}

Received: 22 April 2020, Accepted: 22 June 2020, Published online: 05 August 2020

\begin{abstract}
In the past years, Khuzestan province which is located in the southwest of Iran has experienced severe droughts. Drought can be explained by its characteristics known as duration or severity. However, combination of the two features by probabilistic approach is appeared to be a well improved method to describe the phenomena. The aim of this study is to provide a more accurate statistical method of determining drought based on simultaneous analysis of two drought characteristics. Here, precipitation data from twenty stations were used to determine drought characteristics, by Standardized Precipitation Index (SPI). Joint probability function of two variables were built via copula functions. The drought return period was calculated in the form of two scenarios. The first scenario is, based on an assumption that drought is recognized by at least one of the two specific characteristics. Drought in the second scenario is distinguished by the two characteristics in a joint probabilistic form. According to research results, there was no significant difference between the north and south of Khuzestan in the study of single characteristics of drought. While analyzing two characteristics of the drought, the return period in the north was shorter than the south. The return period of droughts in the east was always shorter than in the west. The drought return period varies from 30 to 52 months and 50 to 87 months for the first and second scenarios, respectively.
\end{abstract}

Keywords

drought, return period, Khuzestan, copula functions, standardized precipitation index, spatial analysis

\section{Introduction}

Drought seems to be the biggest challenge among natural disasters. So far, it has affected extensive areas in different parts of the word and especially in Africa and Asia for a longtime. Various drought definitions have been introduced. But there is a quadruple classification that is more popular [1,2]. 1) Meteorological drought: When the precipitation decreases and the temperature rises, 2) Hydrological drought: In this drought category, hydrological variables are important, and it occurs when runoff or volume of water reservoirs decreases. 3) Agricultural drought: In this drought category, soil moisture is important, and it occurs when soil moisture decreases causing crop losses. 4) Socio economic drought: In which drought causes economic and social negative effects on people's lives. For example, farmers' income decreases [3-5].

In Recent decades, drought has occurred frequently in Iran $[6,7]$. As a supreme threat, vulnerability has been strongly increased by drought duration growth, especially in rural areas [8]. Researches acknowledge worried conditions regarding the drought growing trend in Iran, particularly in extreme state happened in recent years $[9,10]$. In southwest of Iran, Khuzestan province which holds major water resources of the country [11], has revealed a frequent drought occurrence during the last decades [12]. At least one extremely severe drought took place in the last fifteen years in Khuzestan $[13,14]$. The average temperature and precipitation in Khuzestan are $23.3{ }^{\circ} \mathrm{C}$ and $322.6 \mathrm{~mm}$ per year respectively [15]. Due to extensive drought damage in Khuzestan province, providing a method for determining the return periods of droughts (with different characteristics) will be a powerful tool for decision makers. Therefore, the main objective of the study is to provide a method for estimating the drought return period in Khuzestan province.

Drought management is a function of drought characteristics cognition. Perception of drought characteristics (e.g. duration and severity) are powerful tools for 
decision makers. These features are determined on the base of defined indicators. Many indices are presented in drought estimation and the researchers have been reviewed these indices [16-20]. Undoubtedly, the most widely used drought index is Standardized Precipitation Index (SPI). SPI was proposed to compute drought periods by Mckee et al. [21], drought is occurred if SPI is negative and be less than -1 at least once in its duration. Drought duration and severity based on SPI and their best distribution functions were studied by Shiau [22]. Afshar et al. [23] benefited joint probability copula functions to compute the drought return period. They applied SPI, run theory and copula functions to specify the joint probability functions. However, return period were calculated conditionally. Liu et al. [24] applied Standardized Precipitation Evapotranspiration Index (SPEI) to estimate drought duration and its severity. They applied Akaike [25] information criterion to find the best distribution function. Brito et al. [26] estimated the drought based on SPI and Vegetation Health Index (VHI) indices in Brazil. Three drought characteristics including frequency, duration and severity were calculated based on each index. Each characteristic was individually analyzed, and drought trends were determined. Hameed et al. [27] calculated drought characteristics based on Standardized Precipitation Evapotranspiration Index (SPEI) in Iraq. The map of each drought characteristic was drawn, and the dry periods were determined. Yang et al. [28] determined the drought characteristics in China with a new combined index. They used the copula functions to combine drought characteristics, which resulted in high accuracy of estimates.

Consequently, in most researches, linear or weighting method has been used in the composition of drought characteristics. Also, in most cases, drought trends have been investigated and not the return periods of droughts. Considering these points, in the present study, the nonlinear structure of the copula functions was used to combine drought characteristics. Using the Copula functions, the probability of the occurrence of different droughts and their return periods are calculated.

Applying more than one drought characteristic increases knowledge and thus increases the accuracy of estimates. Among the methods of combining variables, Copula functions have more reliable results due to maintaining the statistical structure of variables, which is why these functions have been used in this study. Another important contribution of this study was the calculation of the return period in two statistical states. By comparing the results, the effect of drought on different areas can be determined.
Kavianpour et al. [15] analyzed the temporal-spatial performance of the combined drought index. However, in this study, an attempt has been made to calculate the drought return period based on the common probability function of drought characteristics.

First the study area is introduced, and then the research methodology is reviewed. In the next section, the results of the application of the proposed method in Khuzestan province are presented and finally conclusions are drawn.

\section{Methodology and study area}

In this study, SPI index is used to obtain drought features (duration and severity), then the joint probability function was formed by copula functions. The drought return period was examined under different conditions. Consequently, here the methodology is completely explained.

Monthly precipitation data derived from 20 rain gauge stations in Khuzestan province, southwest of Iran, between 1967 to 2012 was used to implement the proposed method. The location of Khuzestan in the country, its rain gauge stations, and spatial precipitation distribution are illustrated in Fig. 1. Annual measured precipitation occurs from $154 \mathrm{~mm}$ to $1149 \mathrm{~mm}$ and shows almost $95 \%$ between November to April. Monthly rain distribution pattern is shown in Figs. 2 and 3.

In current study, the precipitation data were collected and the data gaps in the rainfall time series were found. The data gaps for each station were filled according to the best fitted distribution function. The distribution functions were determined by Kolmogorov-Smirnov and Chisquared tests. The random values were generated and placed in the series by Inverse Distance Weighting (IDW) interpolation through three adjacent stations. Interpolated data were ranked in descending order along with generated data to fill the blank time steps [29, 30]. Eventually, rainfall time series were completed to compute the drought index. Fig. 1 provides a typical example of observed and generated precipitation data series.

Standardized precipitation index (SPI) is the most usable index in drought monitoring for its simplicity [21], and its accuracy compared to other indicators [31,32]. To follow the process, cumulative distribution function was first computed by gamma distribution function, fitted into time series. Then, SPI values were then calculated by transforming data into an inverse normal distribution function with mean and variance values of 0 and 1 , respectively. Table 1 shows the SPI classification in different drought conditions. Detailed explanation is referred to Guttman [33]. 


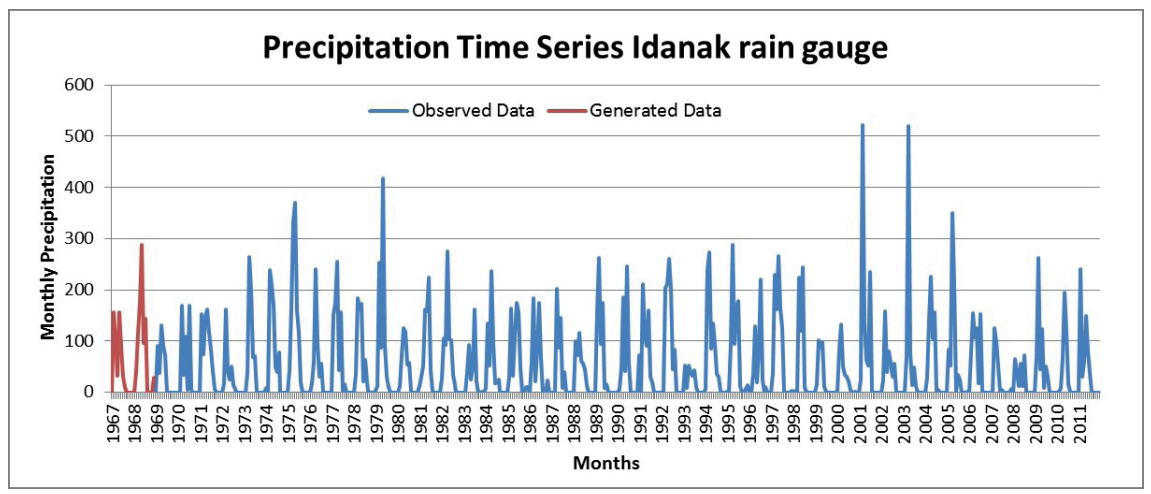

(a)

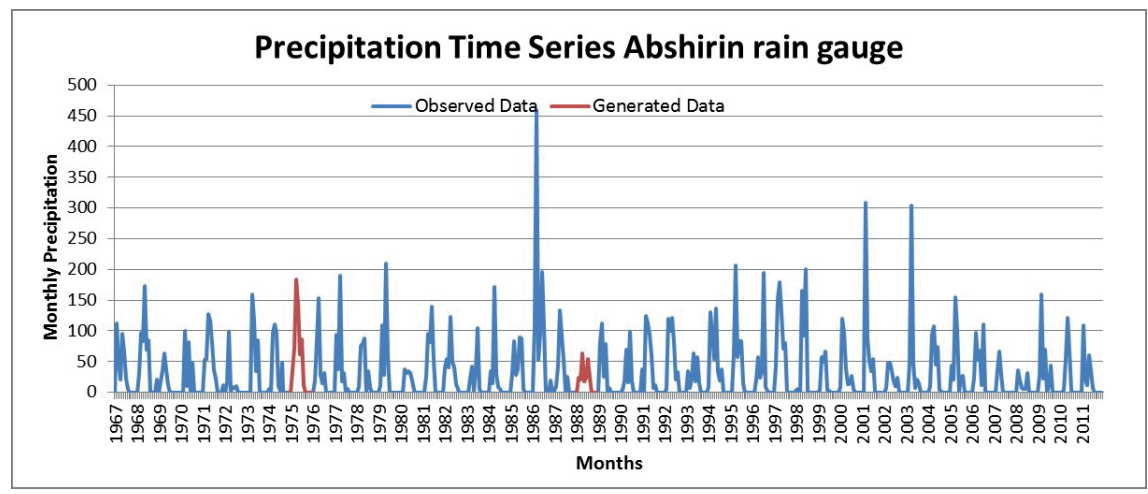

(b)

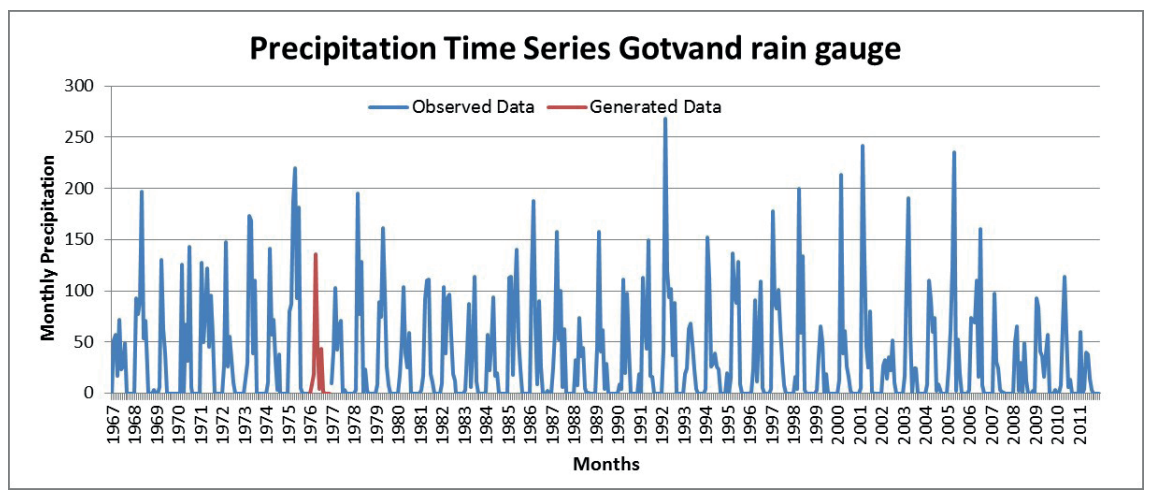

(c)

Fig. 1 Typical examples of observed and generated gaps in time series

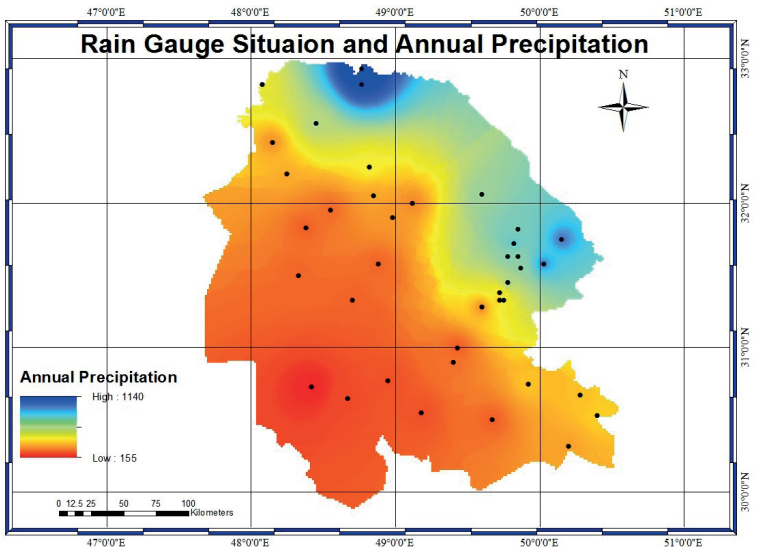

Fig. 2 Khuzestan rain gauges and spatial precipitation distribution
Yevjevich [34] presented a method based on Run theory to calculate the drought characteristics. Fig. 4 illustrates the drought specification definition by Run theory in the forms of drought duration and its severity.

Dry and wet periods were determined based on SPI. Every drought has a starting point and an end point. The distance between these two points is equal to the drought duration. For example, if the distance between these two points is four months, the duration of the drought is four months. In this example, the severity of drought is the sum of the index value in each of the four months. According to Shiau [22], if $D$ and $S$ represent respectively the drought duration and severity, we have. 


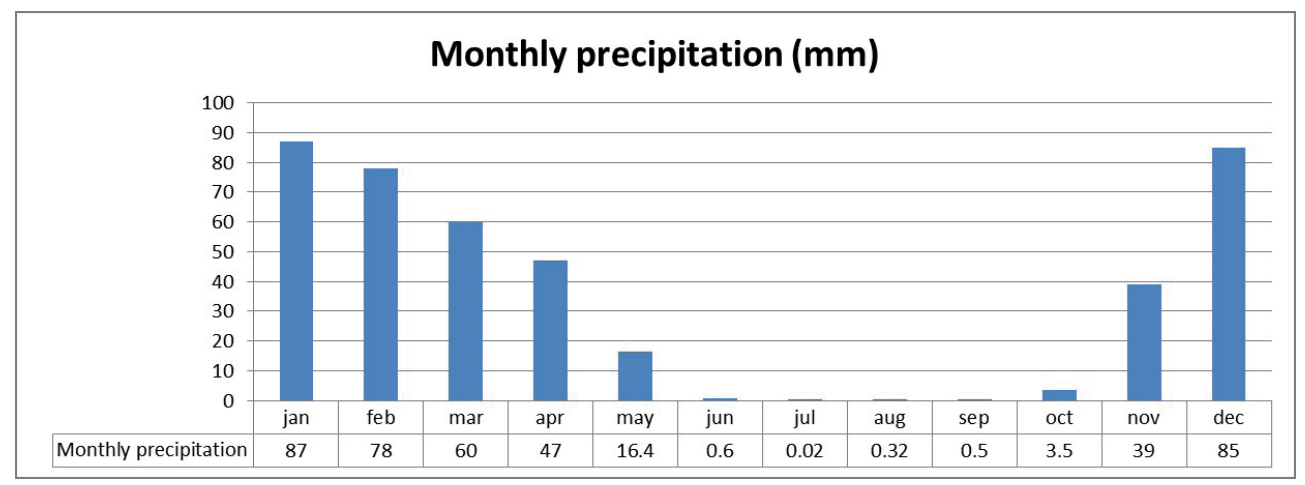

Fig. 3 Monthly rain distribution in Khuzestan rain gauges

Table 1 Drought categories based on the SPI

\begin{tabular}{lc}
\hline SPI & Classification \\
\hline SPI $>2$ & Extremely wet \\
$2>$ SPI $>1.5$ & Very wet \\
$1.5>$ SPI $>1$ & Moderately wet \\
$1>$ SPI $>-1$ & Near normal \\
$-1>$ SPI $>-1.5$ & Moderately dry \\
$-1.5>$ SPI $>-2$ & Severely dry \\
$-2>$ SPI & Extremely dry \\
\hline
\end{tabular}

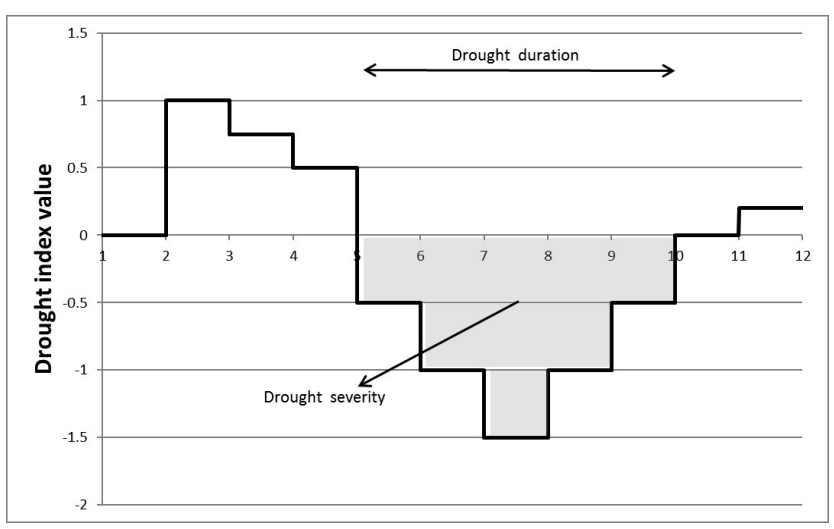

Fig. 4 Drought characteristics based on run theory

$S=-\sum_{i=1}^{D} S P I_{i}$

In this equation, SPIi denotes the SPI value for the ith time step. Both duration and severity follow specific distribution functions $F(D)$ and $F(S)$. Best distribution functions were selected by Kolmogorov Smirnov and Chisquared tests. The procedure follows by calculating the joint probability function.

$$
\begin{aligned}
& F(D)=P(D \leq d) \\
& F(S)=P(S \leq s)
\end{aligned}
$$

Originally, joint probability function was limited to input variables with identical distribution function. Copula functions are able to model the dependence structure of variables without considering their distribution functions. For distribution functions $F_{x}(x)$ and $F_{y}(y)$ with $x$ and $y$ as variables, the copula function is defined as follows [22]:

$$
F_{x . y}(x \cdot y)=C\left(F_{x}(x) \cdot F_{y}(y)\right) \text {. }
$$

Copula functions are divided into two general categories: parametric and nonparametric. Parametric functions are preferred because their parameters are computable. The parameter makes the Copula functions more accurately fit on the input variable. Archimedean functions are the most widely used parametric Copula functions due to their symmetry and ease of calculation. In this study, three bivariate Archimedean copula functions named Frank, Gumbel and Clayton were applied. These functions are indicated in Table 2.

Empirical Cunnane plotting position was used to calculate empirical probability of drought characteristics. It is an unbiased plotting position and useful for all distribution functions.

$P_{i}=\frac{i-\alpha}{N+1-2 \alpha} \quad \alpha=0.4$,

Table 2 Applied copula functions

\begin{tabular}{lccc}
\hline $\begin{array}{l}\text { Copula } \\
\text { name }\end{array}$ & Copula function & Variables & $\begin{array}{c}\text { Conside- } \\
\text { rations }\end{array}$ \\
\hline $\begin{array}{l}\text { Frank } \\
{[35]}\end{array}$ & $C(u, v)=-\frac{1}{\theta} \ln \left[1+\frac{\left(e^{-\theta u}-1\right)\left(e^{-\theta v}-1\right)}{e^{-\theta}-1}\right]$ & bivariate & $\theta \neq 0$ \\
& $C(u, v)=\exp \left(-\left[(-\ln u)^{\theta}+(-\ln v)^{\theta}\right]^{1 / \theta}\right)$ & bivariate & $\theta \geq 1$ \\
$\begin{array}{l}\text { Gumbel } \\
{[35]}\end{array}$ & & \\
$\begin{array}{l}\text { Clayton } \\
{[35]}\end{array}$ & $C(u, v)=\left(\max \left[u^{-\theta}+v^{-\theta}-1,0\right]\right)^{-1 / \theta}$ & bivariate & $\theta \neq 0$ \\
\hline
\end{tabular}


where, $N$ is sample size and $i$ is the rank of datum in small to large order of inputs. Root Mean Square Error criterion (RMSE) was applied to test the fitting likelihood and to find the best copula function to shape the joint probability function. To check the errors, RMSE values were used as follows. Better model has been considered to have the lower RMSE value.

$$
R M S E=\sqrt{\frac{\sum(C V-O V)^{2}}{N}},
$$

where $N$ is the sample size and $C V$ and $O V$ are calculated and observed values, respectively. According to lowest amount of RMSE, the best copula function was selected, and joint probability function was formed. Drought return period is the time interval between two successive drought events. It is calculated in accordance with drought specifications, such as drought return period with 4-month duration or severity higher than five. Sometimes drought is defined as a combination of its characteristics, like drought with 6-month duration and severity upper than 4 . In such situation, a joint probability function is used. The general form of the return period is as follows:

$$
T=\frac{E}{P},
$$

where $T$ stands for drought return period, $P$ is the drought probability occurrence, and $E$ is the expected drought time interval [23]. Time interval is defined as the ratio of total time to the number of drought events. The probability of drought appearance was studied in two categories named common and union. The first considers the probability mode of common form of two drought characteristics. For example, the probability of a drought occurring duration of 6 month and severity of 5. The Second class considers the probability of a drought occurring duration of 6 month or severity of 5. The following equations represent the calculation of these two probability formats.

$$
\begin{aligned}
T(D \geq d \text { and } S \geq s) & =\frac{E}{P(D \geq d \cdot S \geq s)} \\
& =\frac{E}{P(D \leq d \cdot S \leq s)^{\prime}}=\frac{E}{1-P(D \leq d \cdot S \leq s)} \\
& =\frac{E}{1-F(D)-F(S)+F(D \cdot S)} \\
& =\frac{E}{1-F(D)-F(S)+C(F(D) \cdot F(S))}
\end{aligned}
$$

$$
\begin{aligned}
T(D \geq d \text { or } S \geq s) & =\frac{E}{P(D \geq d \text { or } S \geq s)} \\
& =\frac{E}{P(D \leq d \text { or } S \leq s)^{\prime}}=\frac{E}{1-P(D \leq d \text { or } S \leq s)} \\
& =\frac{E}{1-F(D \cdot S)}=\frac{E}{1-C(F(D) \cdot F(S))}
\end{aligned}
$$

Based on the computed probabilities, the values of the return period can be calculated. The flowchart of the methodology is presented in the Fig. 5.

\section{Results and discussion}

\subsection{Standardized Precipitation Index}

In this study, rain time series were used to calculate standardized precipitation index (SPI). For each month, SPI is the integrated 12 former months of rain. Fig. 6 illustrates the SPI values for different rain stations in Khuzestan province. It indicates 45 years frequent drought occurrence in Khuzestan.

\subsection{Drought characteristics}

Drought characteristics in the forms of duration and severity were calculated and the results were provided in this work. Drought duration is referred to negative SPI and severity is referred to the summation of SPI in drought time steps. Average drought duration and severity in rain gauges are shown in Fig. 7. The longest drought phenomenon in rain gauges was occurred in Mollasani with a duration of 68 months and severity of 94.5. Number of drought occurrence varies from 20 in Botvand station to 30 in Talezang gauge. Average of drought duration and severity are 10 months and 8.5 , respectively.

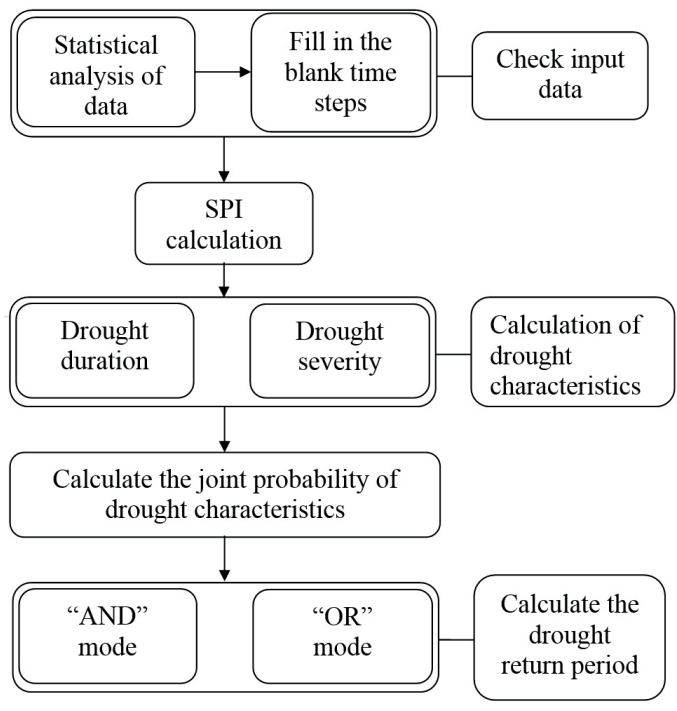

Fig. 5 The flowchart of the methodology 


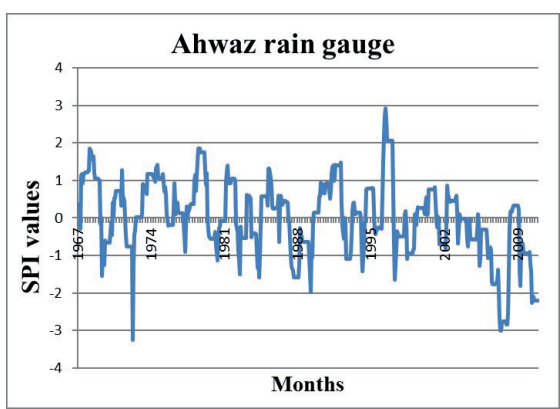

(a)

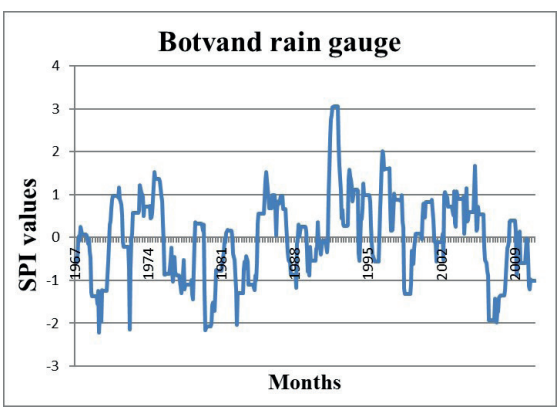

(d)

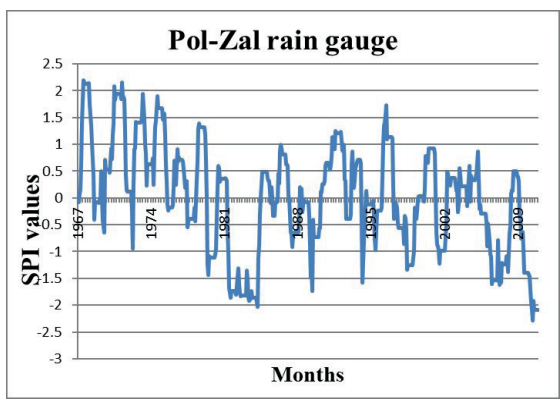

(g)

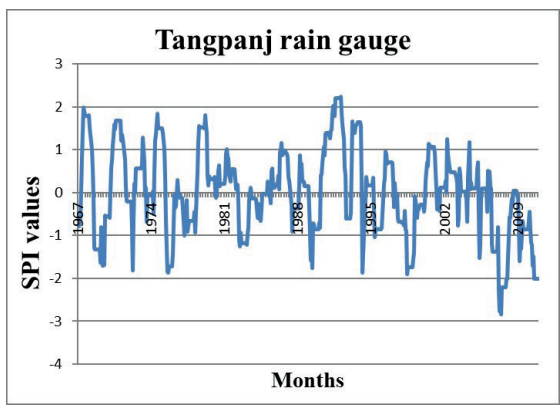

(j)

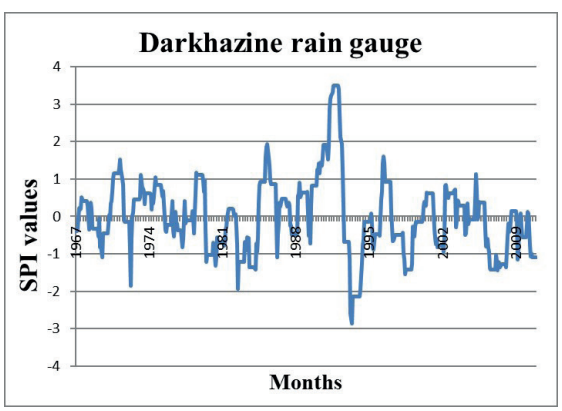

(m)

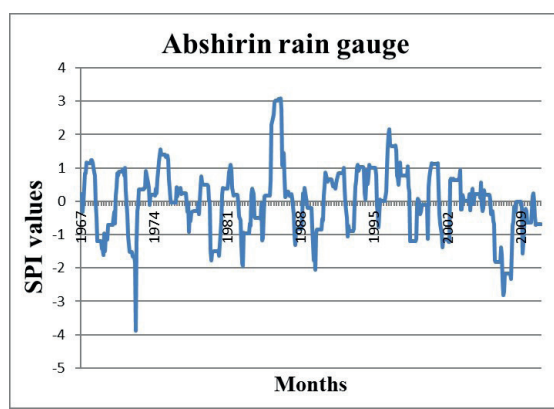

(b)

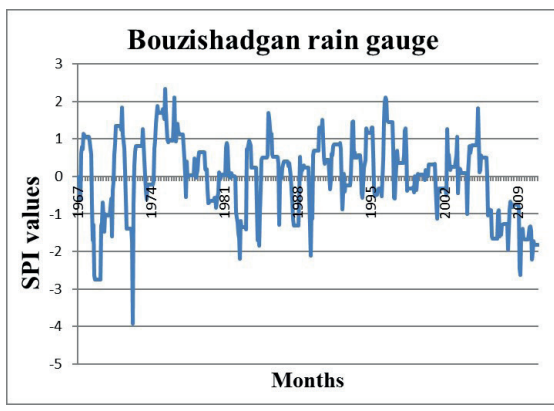

(e)

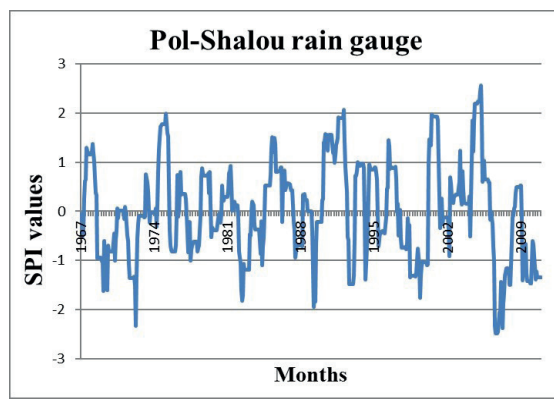

(h)

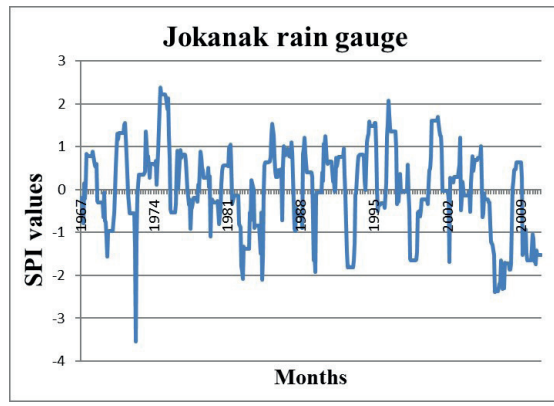

(k)

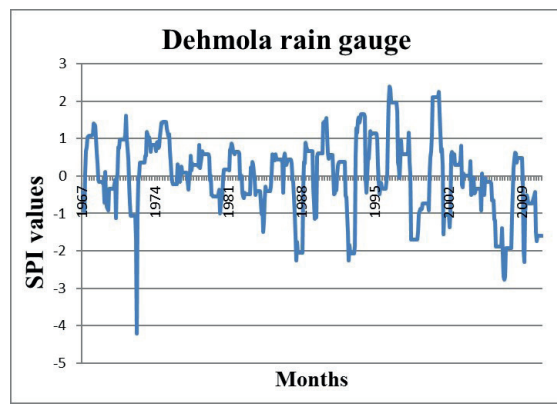

(n)

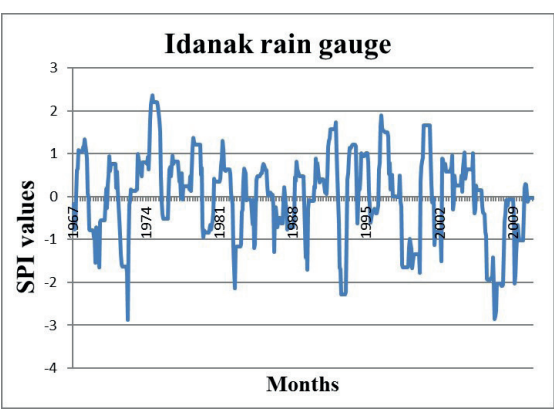

(c)

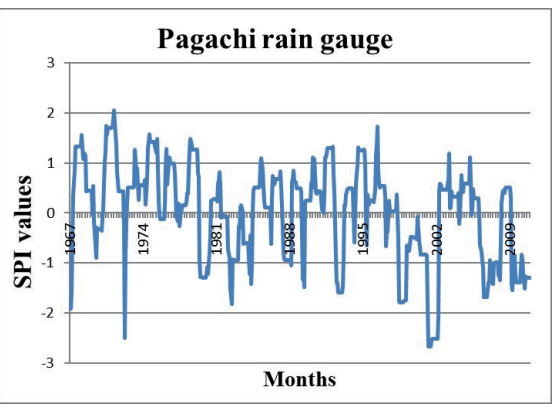

(f)

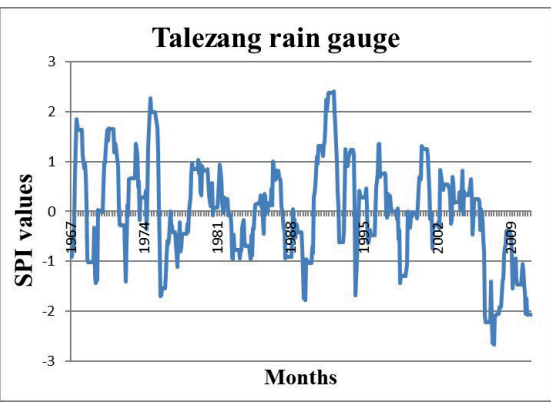

(i)

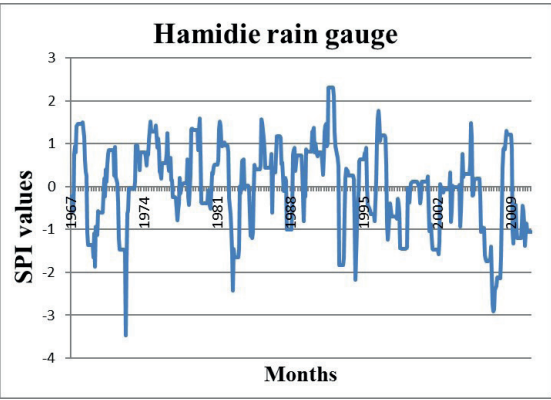

(1)

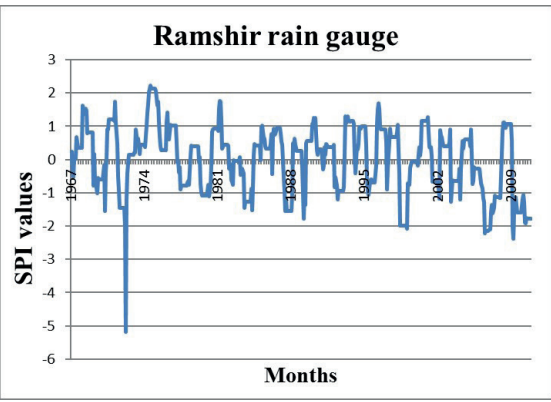

(o)

Fig. 6 Calculated monthly SPI index for different rain gauges in Khuzestan province (a-o) 


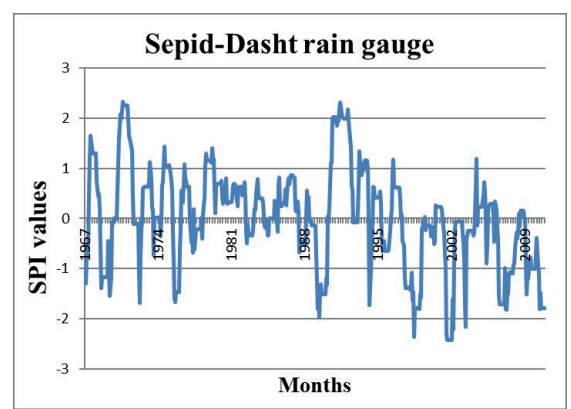

(p)

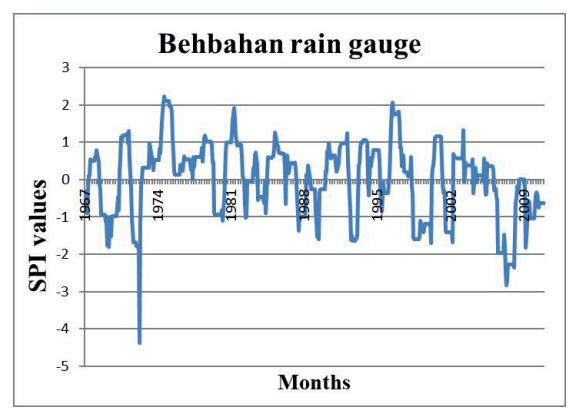

(q)

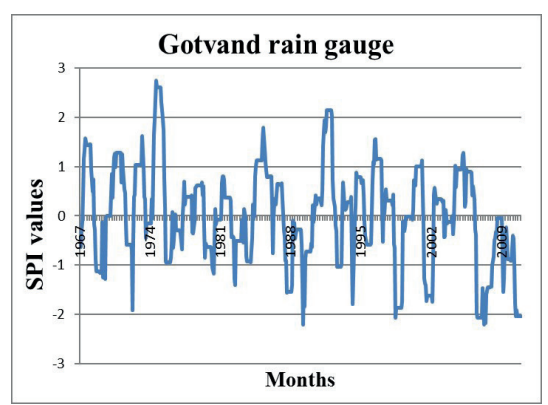

(r)

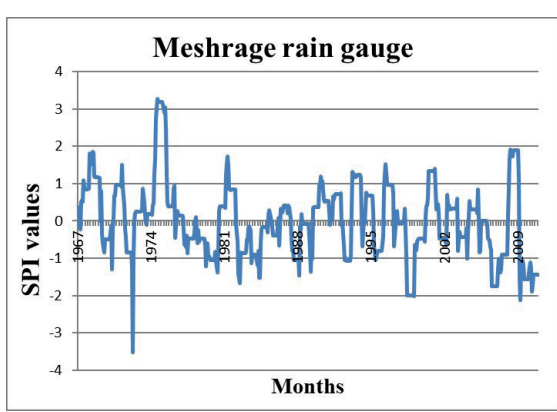

(s)

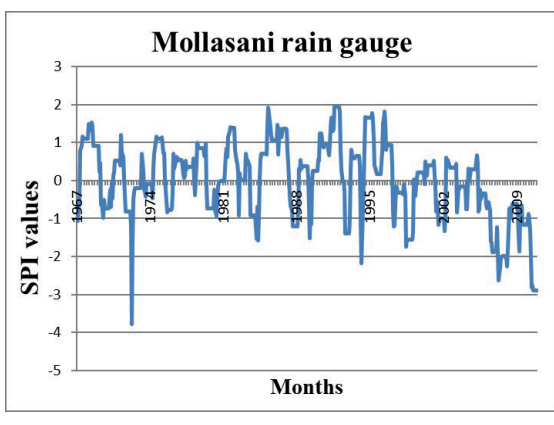

(t)

Fig. 6 Calculated monthly SPI index for different rain gauges in Khuzestan province (p-t)

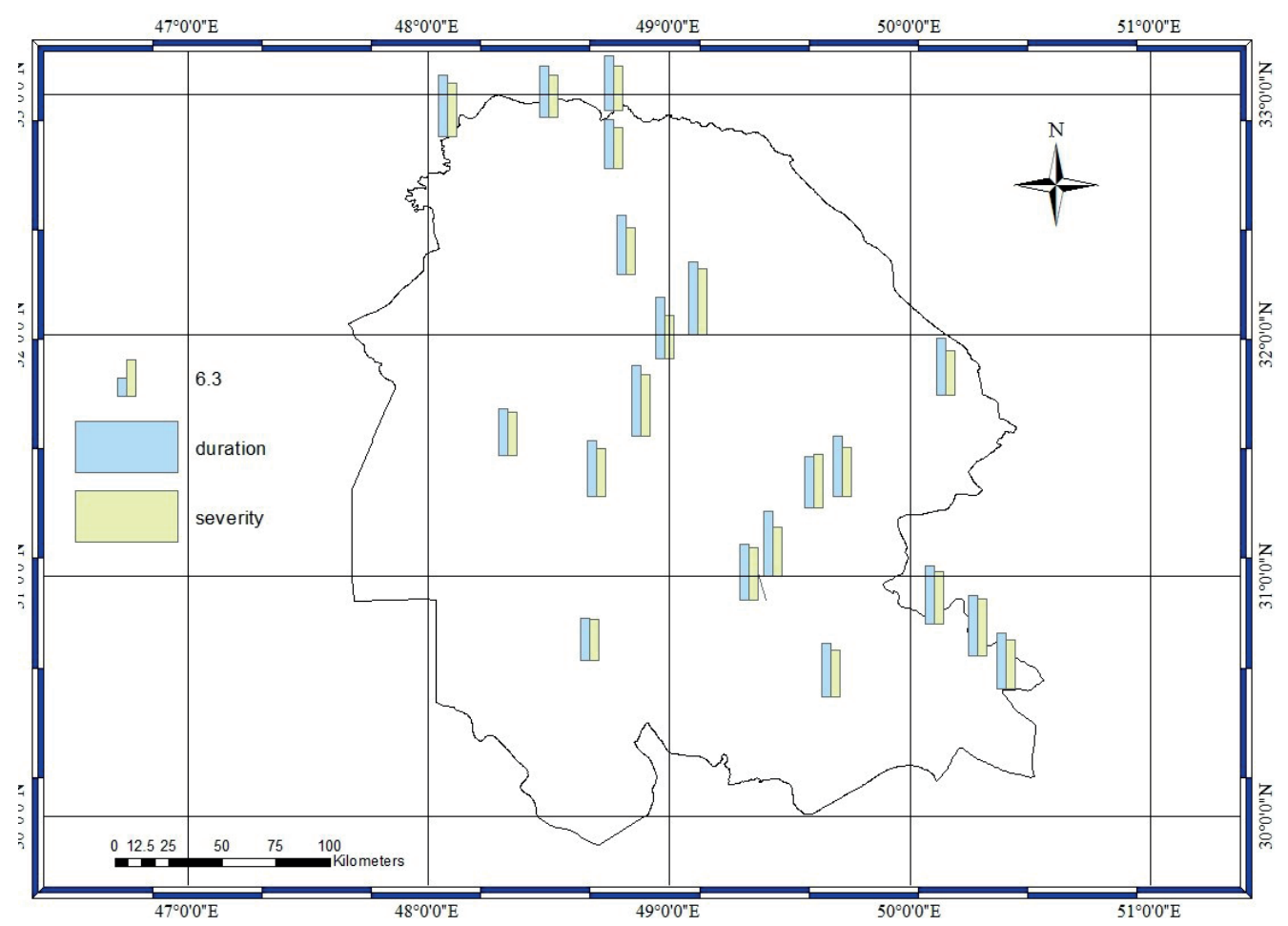

Fig. 7 Drought duration and severity in rain gauge stations

\subsection{Fitting distribution function}

The best fitted distribution function of input variables is necessary for computing joint probability function. Whatever the distribution function has a better fit on data, the calculated probability is more accurate. Therefore, in this study, the best distribution functions were selected by examining more than forty probability distribution functions by EasyFit software. The abundance of each distribution function is reported in Table 3. In Fig. 8, two fitted distributions are illustrated. The Best distribution is used to calculate the joint probability function. 
Table 3 Distribution abundance in drought characteristics

\begin{tabular}{lccc}
\hline Drought Duration & \multicolumn{3}{c}{ Drought Severity } \\
\hline $\begin{array}{l}\text { Distribution } \\
\text { Function }\end{array}$ & Abundance & $\begin{array}{c}\text { Distribution } \\
\text { Function }\end{array}$ & Abundance \\
Gen Pareto & 9 & Gamma & 8 \\
Generalized & 3 & Weibull & 7 \\
Extreme Value & 2 & Beta & 3 \\
Weibull & 2 & Log Normal & 2 \\
Log Logistic & 2 & & \\
Exponential & 1 & & \\
Gamma & 1 & & \\
Generalized & & & \\
Extreme Value & & & \\
\hline
\end{tabular}
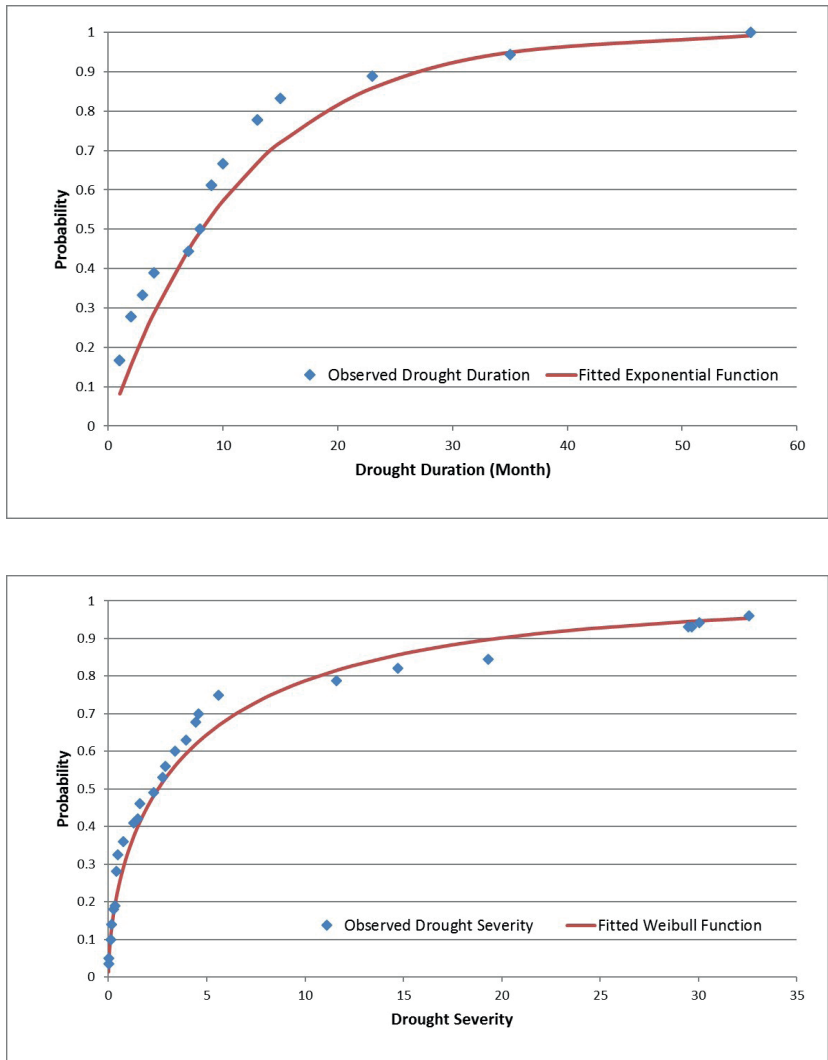

Fig. 8 Examples of best fitted distribution functions

\subsection{Joint probability function}

The research is completed by using copula functions to combine best fitted distribution functions. The functions combine variables with different type of distribution functions which is a main reason of their popularity. Best fitted distribution functions of each drought characteristics were imported to copula functions. Based on Table 2, three Archimedean copula named Clayton, Gumbel and Frank were used to determine the joint probability. Supported by the best fitted distribution function on drought characteristics, Kendall rank correlation coefficient was computed and used to calculate copula parameter $(\theta)$ by equations in Table 2. Copula functions parameter was found 5.06, 8.13 and 18.45 for Gumbel, Clayton, and Frank, respectively. In Fig. 9, three copula functions

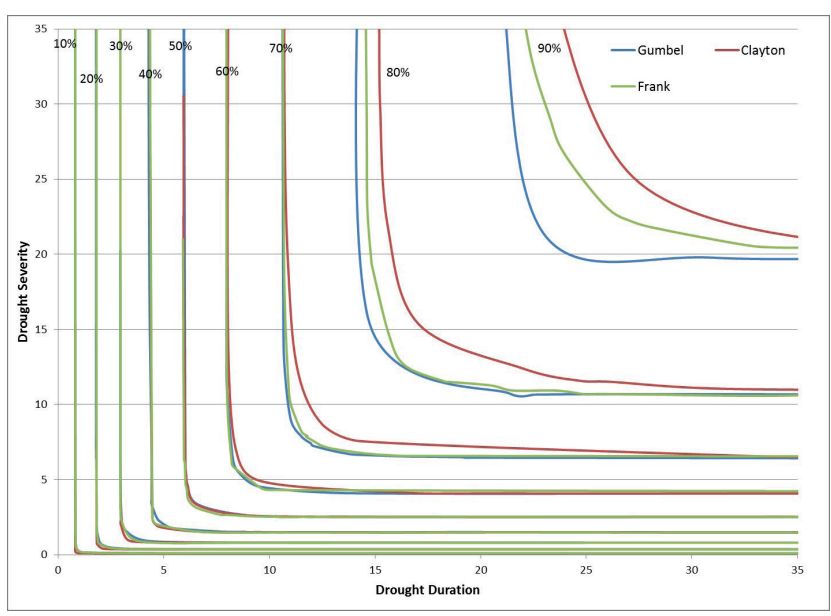

Fig. 9 Different joint probability levels of drought duration and severity

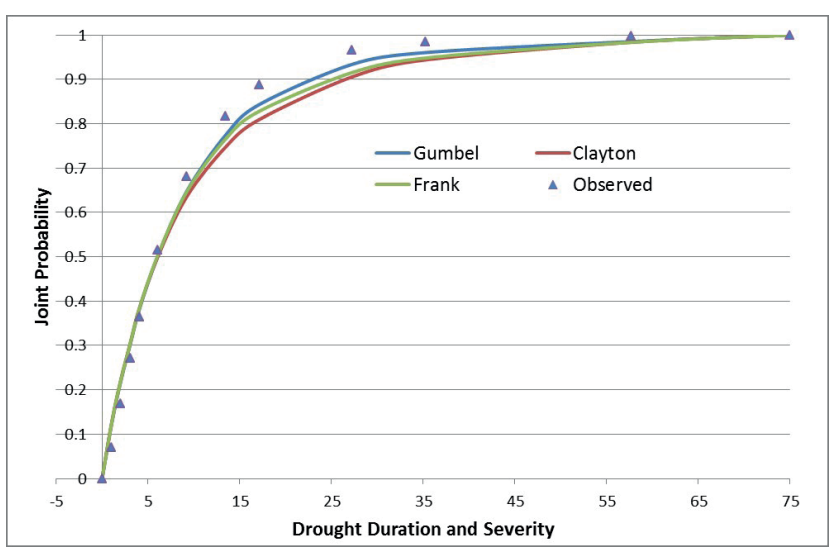

Fig. 10 Cumulative distribution function of three copula functions and observed values

are plotted in different probability levels.

The best fitted copula was determined by RMSE criteria. Cumulative distribution function (CDF) for the three copula functions and observed data are illustrated in Fig. 10. In this figure, horizontal axis refers to drought duration and severity (same value) and the vertical axis represents the joint probability. Results of RMSE values for each copula function are listed in Table 4.

Table 4 Results of RMSE criteria for each copula functions

\begin{tabular}{lccc}
\hline \multicolumn{4}{c}{ Copula functions } \\
\hline \multirow{2}{*}{ RMSE values } & Gumbel & Clayton & Frank \\
& 0.041 & 0.05 & 0.032 \\
\hline
\end{tabular}




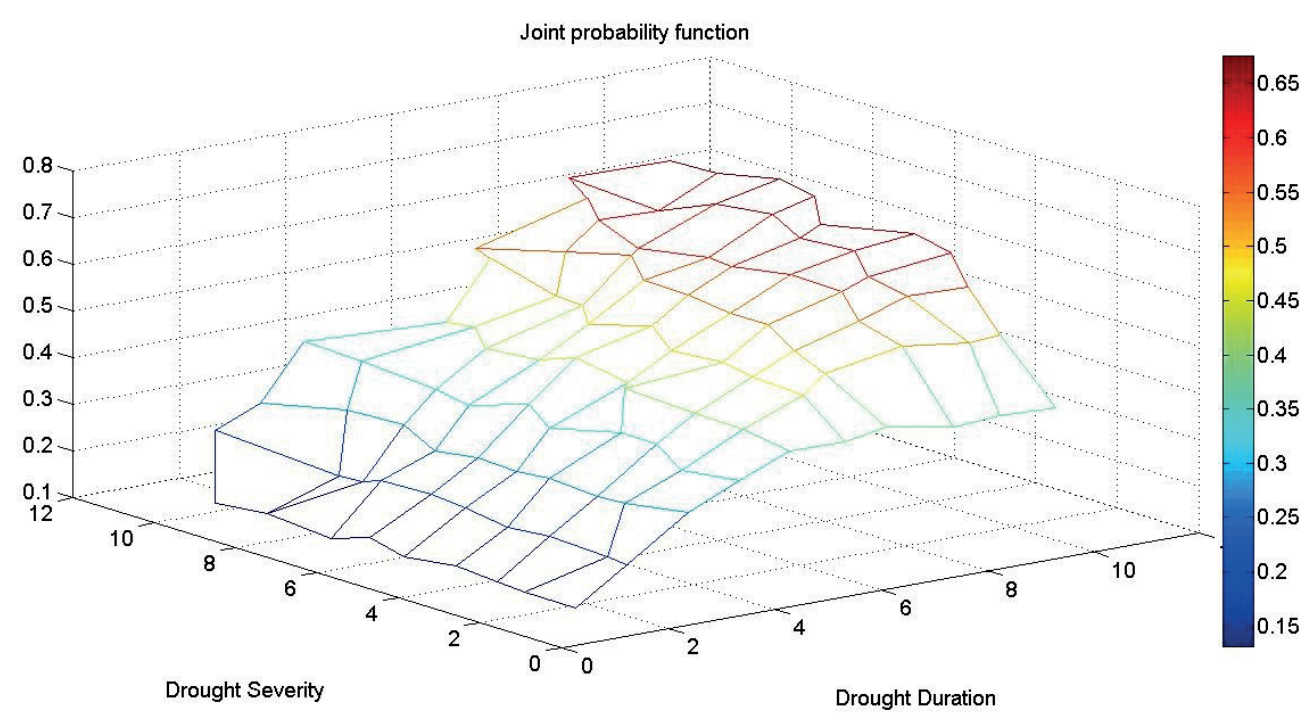

Fig. 11 Joint distribution function in Sepid-Dasht station

Table 4 shows that, Frank copula function introduces lowest RMSE value and therefore, it is selected to calculate the joint probability. Drought duration and severity are presented as inputs to this function and the output is the corresponding probability. The joint probability function of drought variables in Sepid-Dasht station is plotted in Fig. 11 by Matlab software.

Based on selected copula function, different drought conditions have been analyzed to check the probability of drought characteristics and their joint probability. Table 5 shows samples of the results for Sepid-Dasht station. According to the table, the probability of drought occurrence in less than 10 months is $69 \%, 71 \%$ of droughts show a severity less than 5.6, and the joint probability for these two features is equal to $66 \%$.

\subsection{Drought Return Period}

The developed joint probability function was applied to calculate the draught return period (RP). Drought return period mentions the time period for the repetition of a particular drought. In this study, Eqs. (8) and (9) are used to calculate the drought return period. The difference between these equations is referred to their probabilistic

Table 5 Probability of drought characteristics and their joint probability

\begin{tabular}{ccccc}
\hline $\begin{array}{c}\text { Drought } \\
\text { Duration } \\
\text { (month) }\end{array}$ & $\begin{array}{c}\text { Drought } \\
\text { Duration } \\
\text { probability }\end{array}$ & $\begin{array}{c}\text { Drought } \\
\text { Severity }\end{array}$ & $\begin{array}{c}\text { Drought } \\
\text { Severity } \\
\text { probability }\end{array}$ & $\begin{array}{c}\text { Joint } \\
\text { probability }\end{array}$ \\
\hline 10 & 0.69 & 5.6 & 0.71 & 0.66 \\
12 & 0.76 & 2.8 & 0.59 & 0.59 \\
15 & 0.83 & 14.4 & 0.84 & 0.8 \\
23 & 0.92 & 27.7 & 0.91 & 0.89 \\
\hline
\end{tabular}

approach. Equation 8 make uses of two defined attributes to calculate drought return period, while Eq. (9) is based on at least one of the two characteristics. Fig. 12 illustrates the duration and severity for various droughts with different return periods at Sepid-Dasht station, based on Eq. (8). For example, droughts with a six-years return period hold 9 months duration and severity of 5 . According to the figure, increase in the duration to 11 months decreases the severity to 2 , or the severity of 6 for that drought implies 6 months duration. Fig. 13 shows the droughts duration and severity with different return periods at Sepid-Dasht station, based on Eq. (9). Droughts with six years return period show 12 months duration or the intensity of 15 . The results of the two mentioned equations indicate their fundamental differences. The probability of drought based on Eq. (9) is higher than what is obtained from Eq. (8), however, Eq. (9) introduces shorter return period.

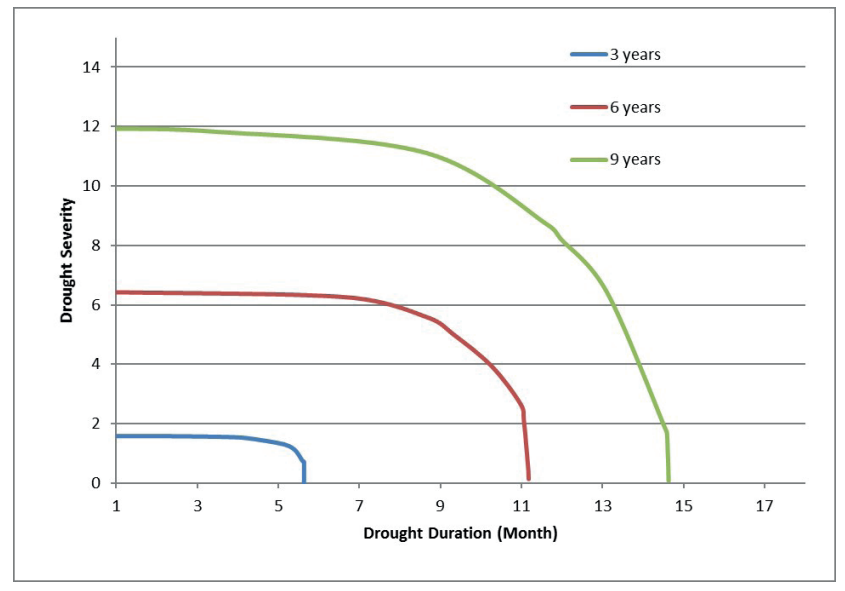

Fig. 12 Drought return period calculated by Eq. (8) at Sepid-Dasht station 
In the chart above, the drought return period of Sepid Dasht station was presented with two probabilistic approaches. Such a chart can be drawn for any station. But ArcMap software was used to better graphically display the results. First, a univariate drought return period of at least six months was determine for each station. The lowest return period was observed in the eastern regions, which indicates the greater impact of the drought in this region. For example, in Polshalou and Jokanak stations, the drought return period, which lasts at least six months, is 31 and 33 months, respectively. In the north of the province, the situation is better, as the six-month drought return period at Talezang and Hamidieh stations is 45 and 40 months, respectively.

The shortest return period indicates a higher likelihood of drought occurrence, which is about 47 months and occurs in Moshragah and Ramshir stations. Eastern regions of Khuzestan had shorter return time, while it was about 80 months in the northern regions. Comparing the two maps in Figs. 14 and 15 suggests different behavior of the stations. This variation is associated with the two

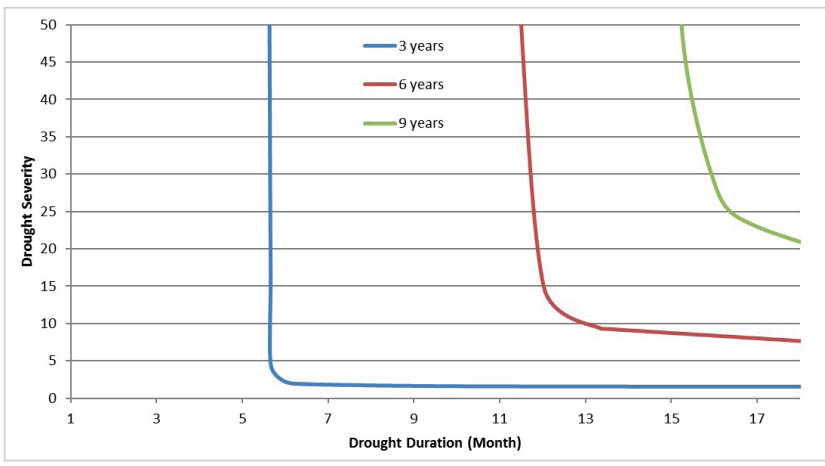

Fig. 13 Drought return period calculated by Eq. (9) at Sepid-Dasht station

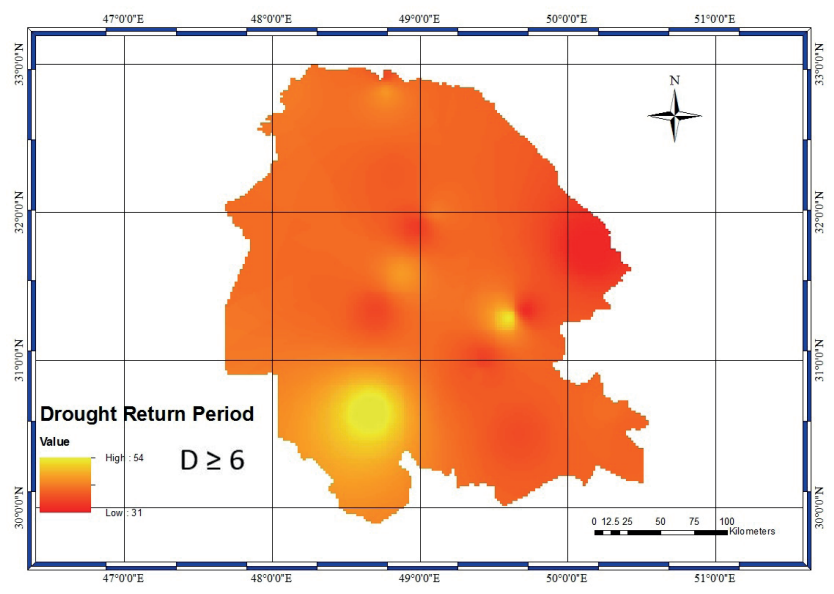

Fig. 14 Univariate return period of drought with duration more than 6 month drought characteristics. In Gotvand and Ramshir stations, drought return period is 36 months, which lasts six months. However, the drought return period with the intensity of six is 61 and 48 months in Gotvand and Ramshir, respectively. These values were 35 and 66 at the Darkhazineh station. For duration $\geq 6$, Pagachi station shows highest drought return period of 51 months in Khuzestan province. In other words, the probability occurrence of this mode at the station is the lowest value in Khuzestan, but drought return period of 61 months occurs for the severity $\geq 6$, which was less than half of the stations. Few stations show similar behavior like Polshalou and Jokanak with return periods of 31 and 53 months, respectively.

The results of simultaneous analysis for the two drought characteristics derived from Eqs. (8) and (9) in Khuzestan are presented in Figs. 16 and 17. In Figs. 16 and 17, it can be seen the effect of increasing intensity and duration on the stations' return periods, simultaneously or individually. According to Fig. 16, the droughts return period with

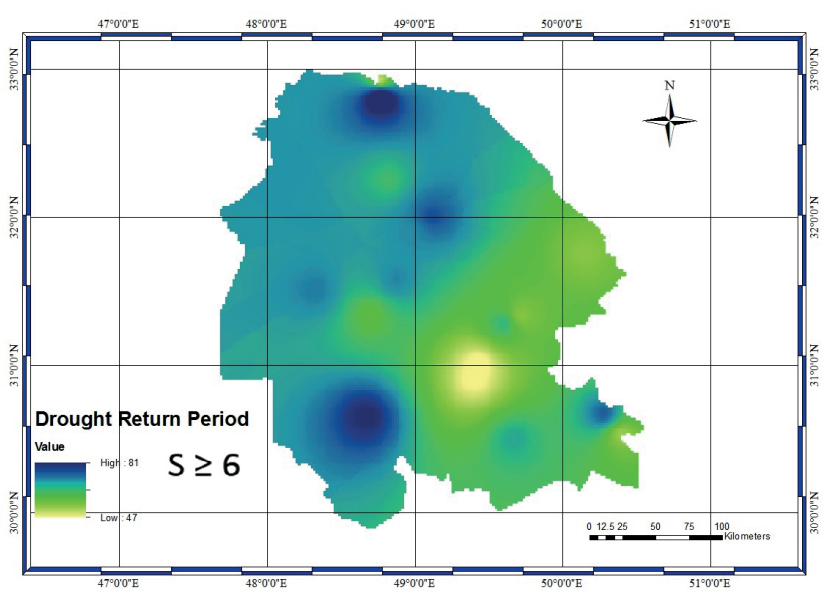

Fig. 15 Univariate return period of drought with intensity more than 6

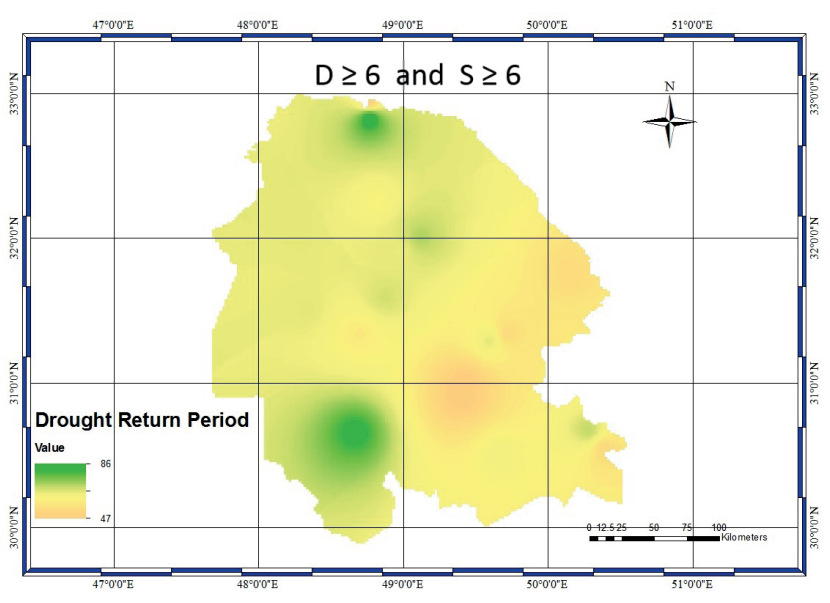

Fig. 16 Bivariate drought return period, Duration $\geq 6$ and Severity $\geq 6$ 


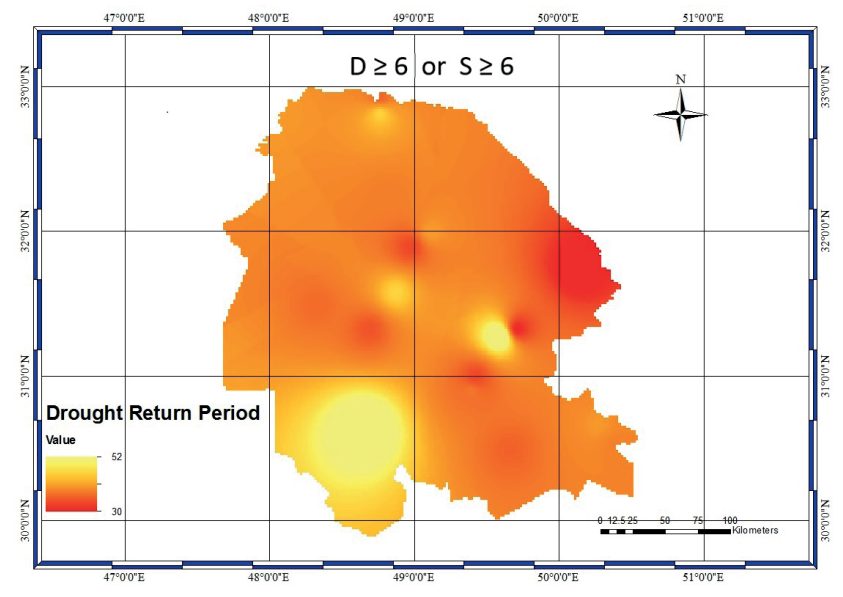

Fig. 17 Bivariate drought return period, Duration $\geq 6$ or Severity $\geq 6$

at least 6 months duration and minimum intensity of 6 is about 52 months in east and center part of Khuzestan (e.g. Polshalou and Ahvaz stations). In Hamidieh (in the west) and Talezang (in the north) stations, the droughts return period is about 65 and 87 months, respectively. According to Fig. 17, the droughts return period that last at least 6 months or show minimum intensity of 6 , are almost identical in $60 \%$ of the stations. In Ramshir, drought return period for duration $\geq 6$ and severity $\geq 6$ (Case 1), and duration $\geq 6$ or severity $\geq 6$ (Case 2 ) is 48 and 38 months, respectively. The station shows lowest value of drought return period in the first case, while it is higher than $50 \%$ of the stations in the second case. Similar conditions at the Abshirin station is realized, where the drought return periods for the 1 st and $2^{\text {nd }}$ cases are 54 and 39 months, respectively. At Darkhazineh station, return periods is 65 months in Case 1, which is the longest period and 35 months in Case 2, which is the least value in the province.

Khuzestan province experiences diverse land uses, which cover extensive agricultural, industrial, and urban activities. The area enjoys major surface and underground water resources. Approximately, $20 \%$ of Iran's surface water resources flows in this region. Therefore, by Using a suitable probabilistic approach and drought characteristics, a proper framework for planning the water resources and reduce the drought effects can be achieved. The results of this study showed the vulnerability in the form of drought return period in different parts of the province as a function of duration and severity variation. In the Khuzestan drought survey, Shokri Koochak and Behnia [36] found that the probability of the continuation of drought conditions rises from west to east. Comparing the drought in north and south of Khuzestan, Borna et al. [37] found that the frequency of drought in the north is more than the south. Both conclusions confirm the results of this study.

Compared to the drought researches in Khuzestan province, Jamalizadeh and Borna [38] also introduced the SPI as the most suitable index for analyzing the drought in Khuzestan. Of course, they had determined the same drought condition in the east and north of the province, but in the proposed method, there was a big difference between the return period of their droughts (Moazed et al. [12]). According to the results of this study, they pointed out the difference between droughts in the east and west of the province.

\section{Conclusions}

To reduce the drought affects, better understanding of drought characteristics is an important task. Drought aspects like duration and severity can be analyzed singly, but probabilistic analysis of their combination impact is more useful. To find the drought periods, the SPI index was computed monthly for twenty rain gauges in Khuzestan province from 1967 to 2012. According to the rain pattern, 12 months SPI was selected and Run theory was applied to determine the drought characteristics. For every station, the best fitted drought characteristics distribution function was selected among various distribution functions like Normal, Logistic, Exponential, Gamma and etc., based on Kolmogorov-Smirnov and Chi-squared statistics.

Non-dependence on probabilistic conditions of input variables in copula functions cause their widespread practice. In this study, three bivariate Archimedean copula functions were applied to form joint probability function drought duration and severity.

In order to find the best function, RMSE criteria was used to compare their results with the Empirical Cunnane plotting position. Drought return period was calculated by two approaches. The joint probability approach assumes jointly occurrence of the two drought variables $(D \geq 6$ and $S \geq 6$ ), but the second approach assumes the occurrence of at least one of the variables ( $D \geq 6$ or $S \geq 6$ ). According to the results, droughts are more intense from west to east of Khuzestan. It also showed the blended and individual effect of intensity and duration on return periods of the stations.

A drought analysis based on a characteristic had different results than simultaneous examination of the two characteristics. For example, in a single survey of drought severity, the northern and southern conditions were almost 
identical. But in the simultaneous analysis of the two drought characteristics, the drought return period in the north was lower than the south. The proposed method can be used in combination of more than two characteristics of drought (like frequency and so on), which will certainly have more accurate results.

\section{References}

[1] Wilhite, D. A., Glantz, M. H. "Understanding: the Drought Phenomenon: The Role of Definitions", Water International, 10(3), pp. 111-120, 1985 .

https://doi.org/10.1080/02508068508686328

[2] Obianyo, J. I. "Effect of Salinity on Evaporation and the Water Cycle", Emerging Science Journal, 3(4), pp. 255-262, 2019. https://doi.org/10.28991/esj-2019-01188

[3] Wahba, S., Kamil, B., Nassar, K., Abdelsalam, A. "Green Envelop Impact on Reducing Air Temperature and Enhancing Outdoor Thermal Comfort in Arid Climates", Civil Engineering Journal, 5(5), pp. 1124-1135, 2019.

https://doi.org/10.28991/cej-2019-03091317

[4] Mulenga, D., Siziya, S. "Indoor air Pollution Related Respiratory Ill Health, a Sequel of Biomass Use", SciMedicine Journal, 1(1), pp. 30-37, 2019.

https://doi.org/10.28991/SciMedJ-2019-0101-5

[5] Tozzi, A., Peters, J. F. "Topology of Black Holes' Horizons", Emerging Science Journal, 3(2), pp. 58-63, 2019.

https://doi.org/10.28991/esj-2019-01169

[6] Moazenzadeh, R., Mohammadi, B., Shamshirband, S., Chau, K. "Coupling a firefly algorithm with support vector regression to predict evaporation in northern Iran", Engineering Applications of Computational Fluid Mechanics, 12(1), pp. 584-597, 2018. https://doi.org/10.1080/19942060.2018.1482476

[7] Ghorbani, A. M., Kazempour, R., Chau, K.-W., Shamshirband, S., Taherei Ghazvinei, P. "Forecasting pan evaporation with an integrated artificial neural network quantum-behaved particle swarm optimization model: a case study in Talesh, Northern Iran", Engineering Applications of Computational Fluid Mechanics, 12(1), pp. 724-737, 2018.

https://doi.org/10.1080/19942060.2018.1517052

[8] Keshavarz, M., Maleksaeidi, H., Karami, E. "Livelihood vulnerability to drought: A case of rural Iran", International Journal of Disaster Risk Reduction, 21, pp. 223-230, 2017.

https://doi.org/10.1016/j.ijdrr.2016.12.012

[9] Abudu, S., Sheng, Z., Sabzi, H. Z., King, J. P. "Drought Scenario Analysis Using RiverWare: A Case Study in Urumqi River Basin, China", Civil Engineering Journal, 4(8), pp. 1837-1850, 2018. https://doi.org/10.28991/cej-03091118

[10] Abdulrazzaq, Z. T., Hasan, R. H., Aziz, N. A. "Integrated TRMM Data and Standardized Precipitation Index to Monitor the Meteorological Drought", Civil Engineering Journal, 5(7), pp. 1590-1598, 2019.

https://doi.org/10.28991/cej-2019-03091355
The main contribution of this study was the calculation of drought return period with two probabilistic approaches and based on the combination of two characteristics of drought. It is recommended that for future research and if the required data was available, other indices or new combined indices can be used to determine the characteristics of drought.

[11] Hamidi Machekposhti, K., Sedghi, H., Telvari, A., Babazadeh, H. "Modeling Climate Variables of Rivers Basin using Time Series Analysis (Case Study: Karkheh River Basin at Iran)", Civil Engineering Journal, 4(1), pp. 78-92, 2018. https://doi.org/10.28991/cej-030970

[12] Moazed, H., Moradzadeh, M., Veysi, S., Kaboli, H. S., Salarijazi, M. "Analysis of drought return period in Khuzestan province, southwest of Iran", Journal of Food, Agriculture \& Environment, 10(1), pp. 642-645, 2012.

[13] Dhawan, S. M., Gupta, B. M., Gupta, R. "Mapping Global Research Output in Big Data during 2007-16", Emerging Science Journal, 2(3), pp. 117-129, 2018. https://doi.org/10.28991/esj-2018-01135

[14] Dayer, E., Pazira, E., Kashkuli, H. A., Sedghi, H. "Changing Furrow Irrigation to Increase Efficiency and Feasibility Study of Reusing Surface Runoff", Civil Engineering Journal, 3(12), pp. 1278-1287, 2018. https://doi.org/10.28991/cej-030957

[15] Kavianpour, M., Seyedabadi, M., Moazami, S. "Spatial and temporal analysis of drought based on a combined index using copula", Environmental Earth Sciences, 77, Article number: 769, 2018. https://oi.org/10.1007/s12665-018-7942-0

[16] Zargar, A., Sadiq, R., Naser, B., Khan, F. I. "A review of drought indices", Environmental Reviews, 19, pp. 333-349, 2011. https://doi.org/10.1139/a11-013

[17] Heim, Jr., R. R. "A Review of Twentieth-Century Drought Indices Used in the United States", Bulletin of the American Meteorological Society, 83(8), pp. 1149-1166, 2002. https://doi.org/10.1175/1520-0477-83.8.1149

[18] Zhang, L. "Big Data, Knowledge Mapping for Sustainable Development: A Water Quality Index Case Study", Emerging Science Journal, 3(4), pp. 249-254, 2019. https://doi.org/10.28991/esj-2019-01187

[19] Oo, H. T., Zin, W. W., Kyi, C. C. T. "Analysis of Streamflow Response to Changing Climate Conditions Using SWAT Model", Civil Engineering Journal, 6(2), pp. 194-209, 2020. https://doi.org/10.28991/cej-2020-03091464

[20] Yaseen, Z. M., Sulaiman, S. O., Deo, R. C., Chau, K.-W. "An enhanced extreme learning machine model for river flow forecasting: State-of-the-art, practical applications in water resource engineering area and future research direction", Journal of Hydrology, 569, pp. 387-408, 2019.

https://doi.org/10.1016/j.jhydrol.2018.11.069 
[21] McKee, T. B., Doesken, N. J., Kleist, J. "The relationship of drought frequency and duration to time scales", presented at Eighth Conference on Applied Climatology, Anaheim, CA, USA, Jan. 17-22, 1993.

[22] Shiau, J. T. "Fitting Drought Duration and Severity with TwoDimensional Copulas", Water Resources Management, 20, pp. 795815,2006

https://doi.org/10.1007/s11269-005-9008-9

[23] Afshar, H. M., Sorman, A. U., Yilmaz, M. T. "Conditional CopulaBased Spatial-Temporal Drought Characteristics Analysis - A Case Study over Turkey", Water, 8(10), Article number: 426, 2016. https://doi.org/10.3390/w8100426

[24] Liu, X.-F., Wang, S.-X., Zhou, Y., Wang, F.-T., Yang, G., Liu, W.-L. "Spatial analysis of meteorological drought return periods in China using Copulas", Natural Hazards, 80, pp. 367-388, 2016. https://doi.org/10.1007/s11069-015-1972-7

[25] Akaike, H. "A New Look at the Statistical Model Identification", In: Parzen, E., Tanabe, K., Kitagawa, G. (eds.) Selected Papers of Hirotugu Akaike, Springer, New York, NY, USA, 1974, pp. 215-222. https://doi.org/10.1007/978-1-4612-1694-0_16

[26] Brito, S. S. B., Cunha, A. P. M. A., Cunningham, C. C., Alvalá, R. C., Marengo, J. A., Carvalho, M. A. "Frequency, duration and severity of drought in the Semiarid Northeast Brazil region", International Journal of Climatology, 38(2), pp. 517-529, 2018. https://doi.org/10.1002/joc.5225

[27] Hameed, M., Ahmadalipour, A., Moradkhani, H. "Apprehensive Drought Characteristics over Iraq: Results of a Multidecadal Spatiotemporal Assessment", Geosciences, 8(2), Article number: 58,2018 https://doi.org/10.3390/geosciences8020058

[28] Yang, J., Chang, J., Wang, Y., Li, Y., Hu, H., Chen, Y., Huang, Q., Yao, J. "Comprehensive drought characteristics analysis based on a nonlinear multivariate drought index", Journal of Hydrology, 557, pp. $651-667,2018$. https://doi.org/10.1016/j.jhydrol.2017.12.055
[29] Hasan, M. M., Croke, B. F. W. "Filling gaps in daily data: a statistical approach", presented at 20th International Congress on Modelling and Simulation, Adelaide, Australia, Dec. 1-6, 2013.

[30] Robledo, C. M. "Mosaic and Trencadís in the Palau De La Música Catalana", Emerging Science Journal, 2(2), pp. 108-116, 2018. https://doi.org/10.28991/esj-2018-01134

[31] Shamshirband, S., Hashemi, S., Salimi, H., Samadianfard, S., Asadi, E., Shadkani, S., Kargar, K., Mosavi, A., Nabipour, N., Chau, K.-W. "Predicting Standardized Streamflow index for hydrological drought using machine learning models", Engineering Applications of Computational Fluid Mechanics, 14(1), pp. 339-350, 2020. https://doi.org/10.1080/19942060.2020.1715844

[32] Theingi, M., Tun, K. T., Aung, N. N. "Preparation, Characterization and Optical Property of $\mathrm{LaFeO}_{3}$ Nanoparticles via Sol-Gel Combustion Method", SciMedicine Journal, 1(3), pp. 151-157, 2019. https://doi.org/10.28991/SciMedJ-2019-0103-5

[33] Guttman, N. B. "Accepting the standardized precipitation index: a calculation algorithm", JAWRA Journal of the American Water Resources Association, 35(2), pp. 311-322, 1999. https://doi.org/10.1111/j.1752-1688.1999.tb03592.x

[34] Yevjevich, V. "An objective approach to definitions and investigations of continental hydrologic droughts", Hydrology papers, 23, Colorado State University, Fort Collins, CO, USA, 1967. [online] Available at: http://hdl.handle.net/10217/61303

[35] Nelsen, R. B. "An Introduction to Copulas", Springer, New York, NY, USA, 2006. https://doi.org/10.1007/0-387-28678-0

[36] Shokri Koochak, S., Behnia, A. "Monitoring and Prediction of Khuzestan Province, Iran Drought Using SPI drought Index and Markov Chain" Journal of Irrigation Science and Engineering, 36(3), pp. 1-12, 2013. (In Persian).

[37] Borna, R., Azimi, F., Saeedi Dahaki, N. "Comparison of SIAP, PN and RAI index for surveying of droughts in Khuzestan province emphasizing the Abadan and Dezful stations", Journal of Physical Geography, 3(9), pp. 77-88, 2010. (In Persian). 